Vol. 14, No. 51, April, 2019, 817-829

\title{
REGIONAL COMPETITIVENESS OF REGIONS (CONCEPT - PILLARS - STRATEGIES AND THEORIES)
}

\author{
Hassanein Mohammed Abu Zaid, Bakr Hashim Bayoumy, Reda Ibrahim Abdel \\ Hamid, Zaghloul Mohamed Al-Saidi and Mohammed Shukry \\ Department of Physical Planning - Faculty of Engineering - Al-Azhar University
}

\begin{abstract}
The regional competitiveness aims to achieve balanced growth in line with the resources available in the region, as it means: the ability of the region to exploit all the resources and components existing in the region to optimize utilization, to provide an environment conducive to development activities, with the aim of achieving a better standard of living and improving the welfare of the people of the region, Supporting infrastructure services and supporting the service sectors, settling economic activities, adopting balanced and coherent economic policies, and developing laws and legislations that regulate and encourage the investment environment), The European Commission has developed a regional competitiveness index based on eleven pillars, each of which is a cornerstone of its own development. The region can not move from one pillar to the next without a preliminary investigation, grouped into three main groups (innovation, efficiency incentives, basic requirements)These three groups are linked by strong linkages to growth within each region and the exploitation of the original strengths to focus on strengthening the economic base of the regions, The success of regional competitiveness requires a diversified economic base, a qualified workforce trained in innovative arts, high technology services, strong links to knowledge and technologybased institutions, a modernized infrastructure, high quality of built-in urban environment, and the ability to develop and implement long-term development Strategies.
\end{abstract}

\section{Keywords: Competitive Advantage, Regional Competitiveness, Regional Competitiveness Pillars And Strategies.}

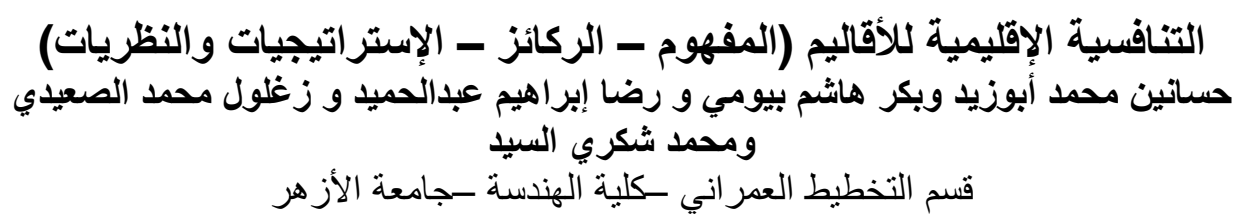


رئيسية (الإبتكار - محفز ات الكفاءة -المنطلبات الأساسية) وترتبط هذه المجمو عات الثناثلاث مع بعضها برو ابط قوية،

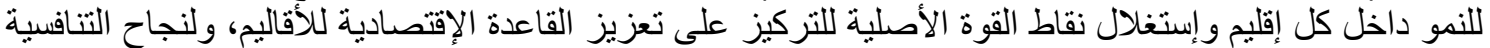

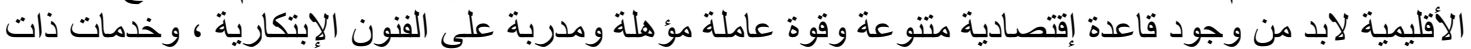

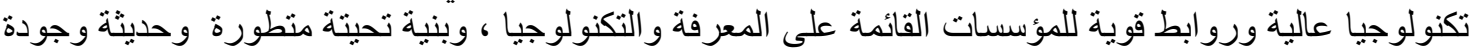
عالية للبيئة العمر انية المبنية ، و القدرة علي تطوير وتنفيذ إستر اتيجيات التنمية ذات التوجه التئية المستقبلي طويل الأمد.

الكلمات المفتاحية : الميزة التنافسية، التنافسية الإقليمية ، ركائز واستراتيجيات التنافسية الإقليمية.

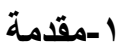

بدأ الإهتمام بتتافسية الأقاليم في العديد من دول العالم بقصد إيجاد نظام متكامل ومتوازن للإن اللتمية العمر انية، قادراً

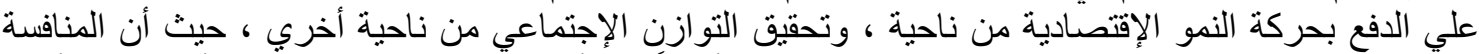

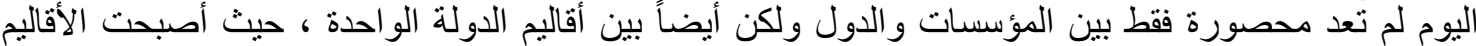

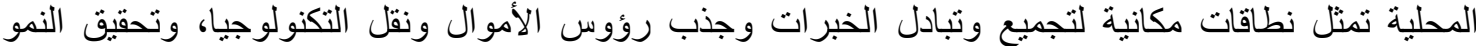

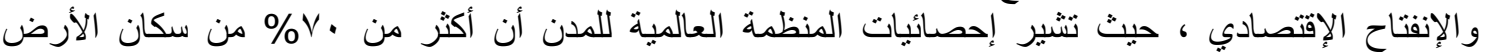

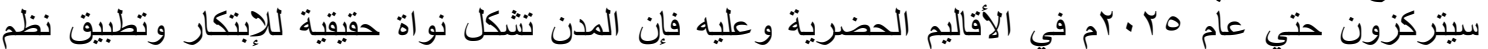

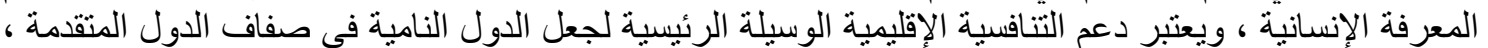

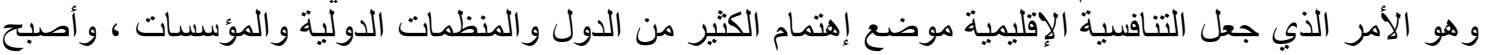

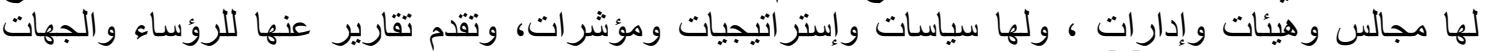

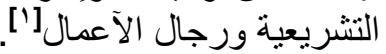
كما بدأ الإهتمام بالتنافسية الإقليمية للأقاليم يتزايد بين العلماء والئية والسياسيين و المستثمرين خلال العقود الأخيرة،

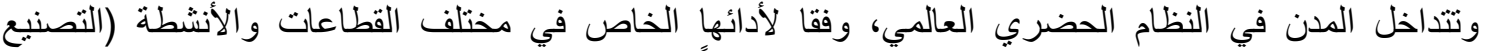

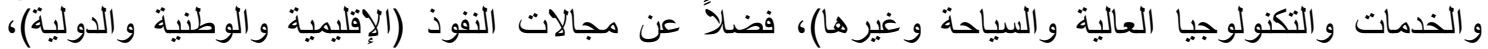

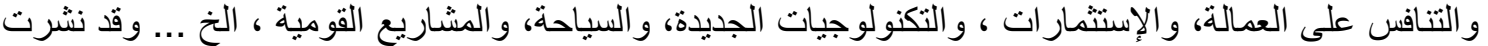

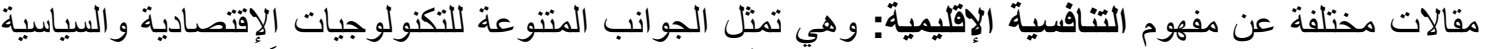

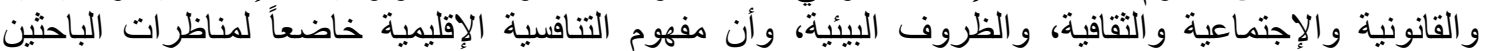

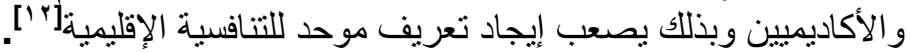

ومما سبق ، فإن الإثكالية البحثية المطروحة والتي تمثل محور الاراسة بهذا البحث تتلخص في التالي:-

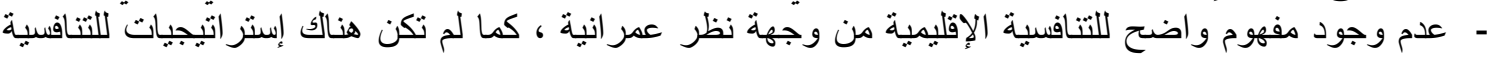

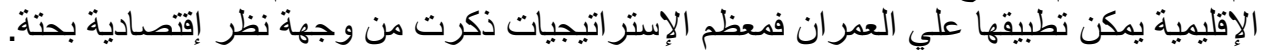

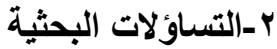
بناءً علي الإثكالية السابقة يمكن وضع مجموعة من التساؤلات التي يجب عليها سياق البحث وهي :

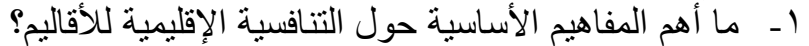

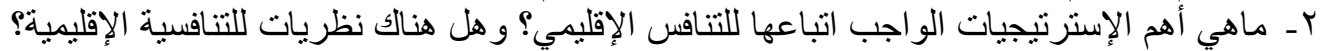

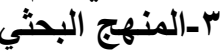
يتبع البحث في سياقه المنهج الإستقرائي لشرح المفاهيم الأساسية للبحث ، والمنهج الإستنباطي بهدف إستناج أهم ركائز و إستر اتتيجيات ونظريات التنافية الإنية الإقليمية.

ع - أهداف الاراسة

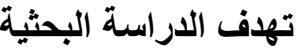

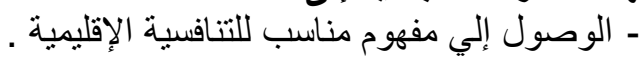
- تكوين تصور متكامل عن التنافسية الإقليمية و إستر اتيجياتها ودمجها في العملية التخطيطة . هـ-مفهوم التنافسية والتنافية الإقليمية للأقاليم

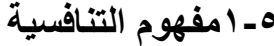

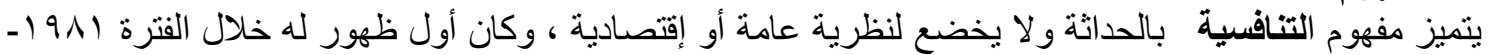
ال IANV ديناميكية التغير المستمر لمفهوم التنافسية نفسة، ففي بداية السبعينات كانت التنافسية ترتبط بالتجارة الخارجية ، 
وفي فترة الثمانيات إرتبطت بالسياسة الصناعية ، بينما إرتبطت في التسعينات بالتقنية، أما حاليًا فهي تركز علي العياتي

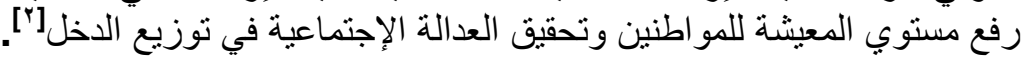

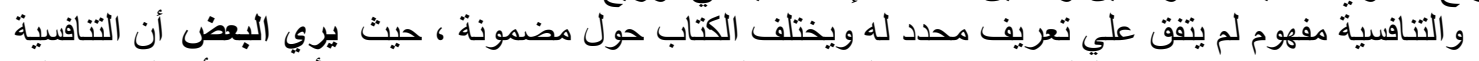

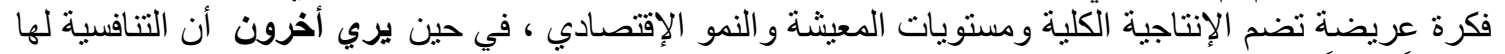

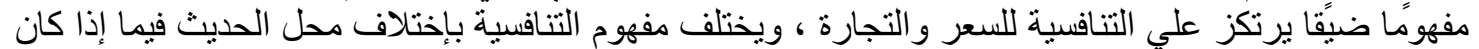

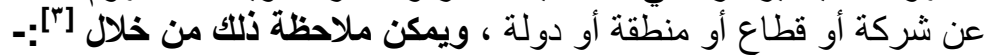

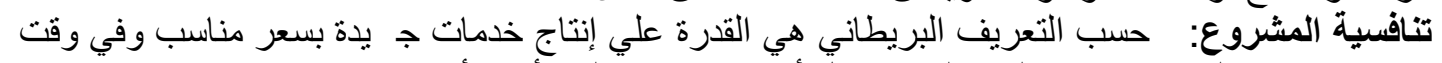

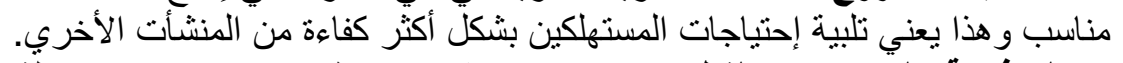

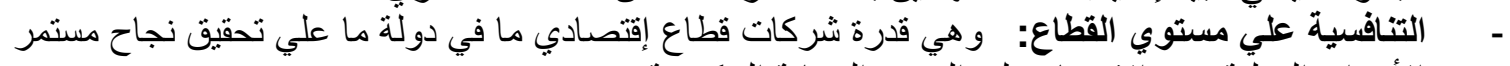

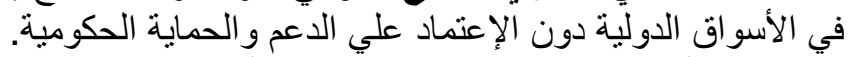

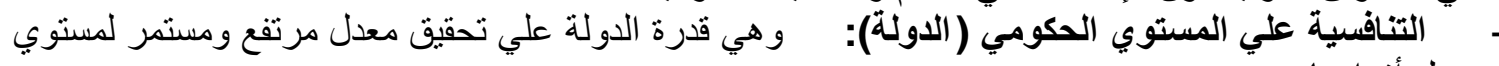

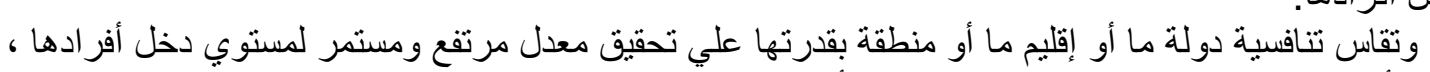

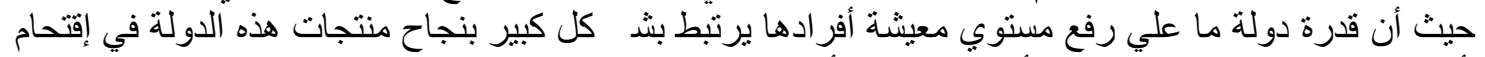
الأسواق الدولية من خلال التصدير أو الإستثمار الأجنبي المبانشر.

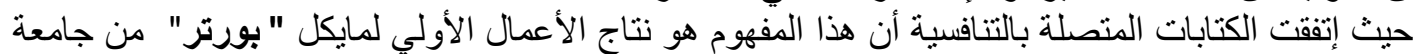

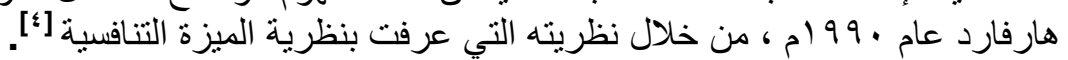

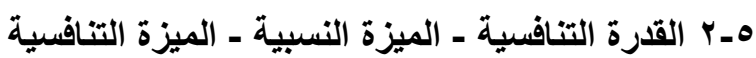

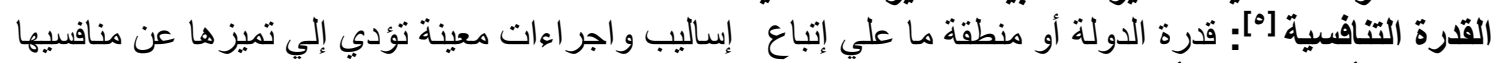

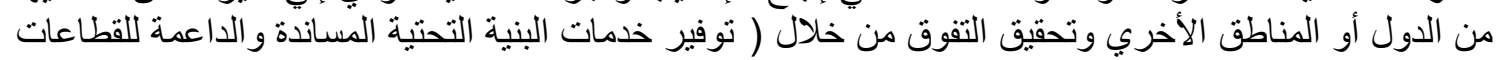

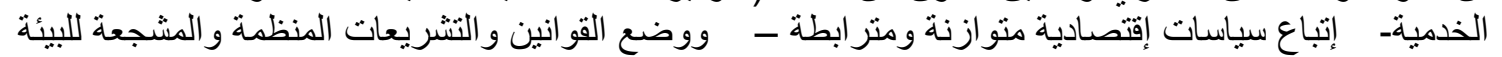
الأستثمارية) .

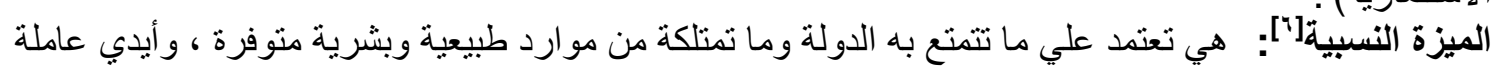

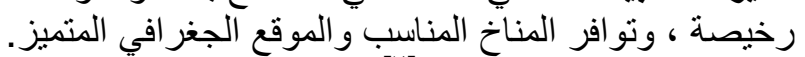

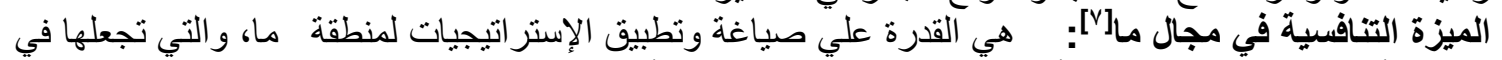

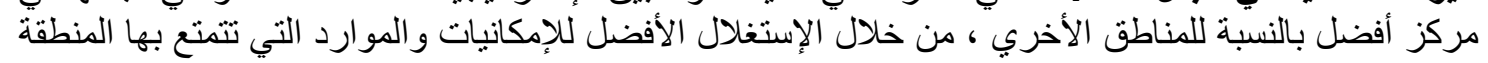

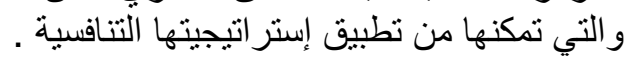

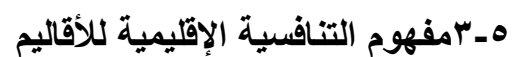
بدأ الإهتمام بالتتافسية الإقليمية للأقاليم بنزية ايد بين العلماء واليمية والسياسيين و المستثمرين خلال العقود الأخيرة، وتتداخل

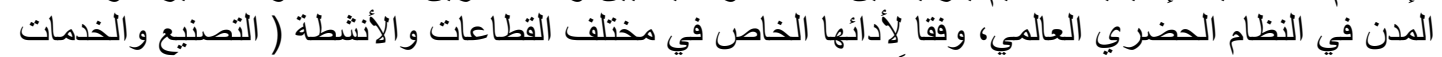

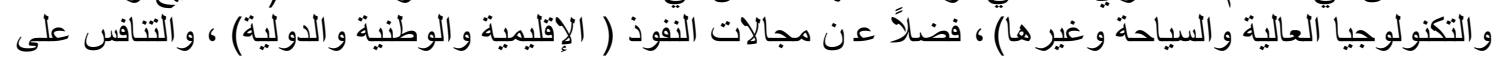

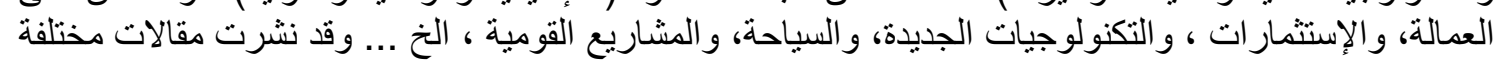

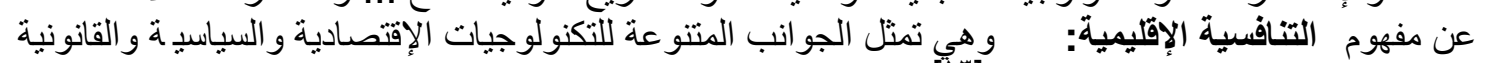

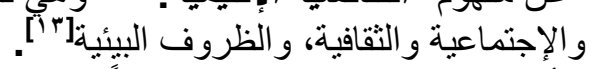

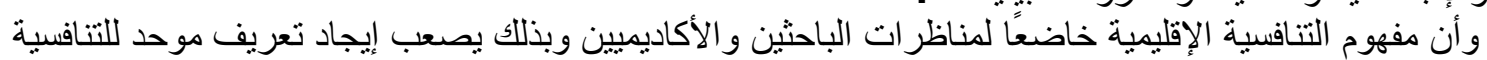

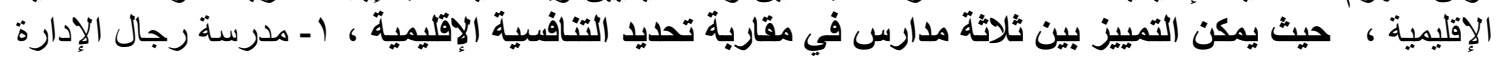

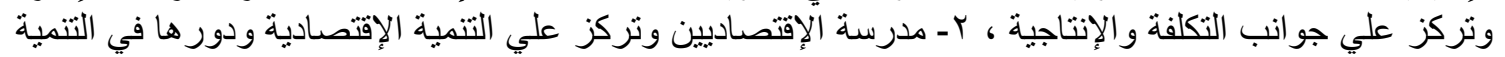

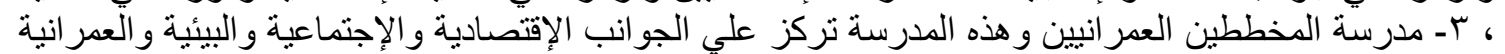

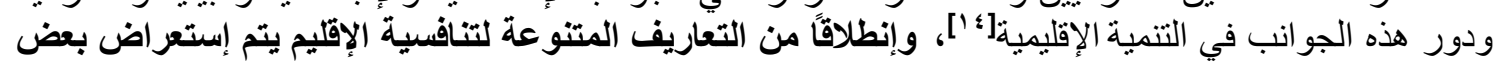

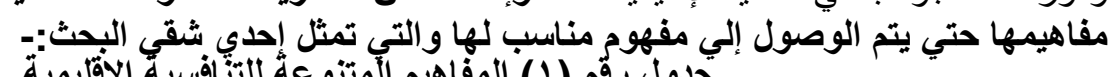

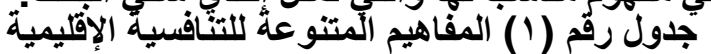

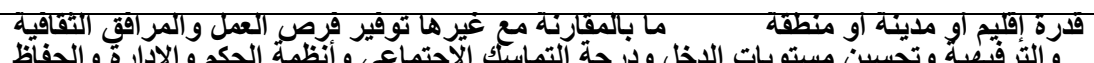

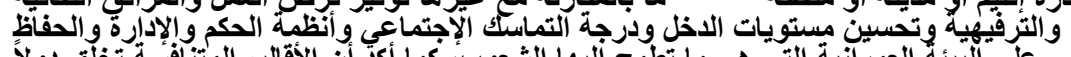

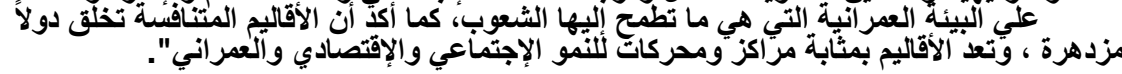
Kresl 


\begin{tabular}{|c|c|}
\hline 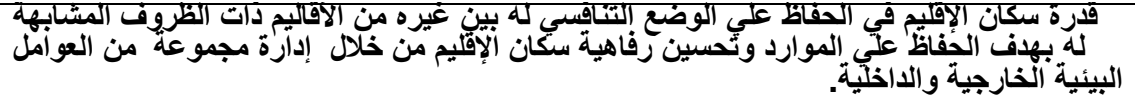 & [10] سينكيني \\
\hline 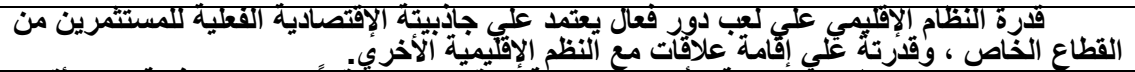 & $\begin{array}{l}\text { Janne } \\
{\left[{ }^{[1]} \text { Antikainen }\right.}\end{array}$ \\
\hline 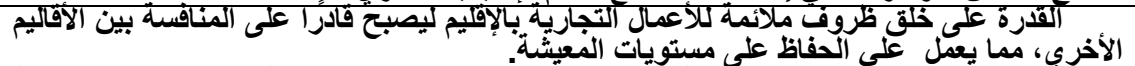 & ${ }^{\left[{ }^{v}\right]}$ Bruneckien \\
\hline 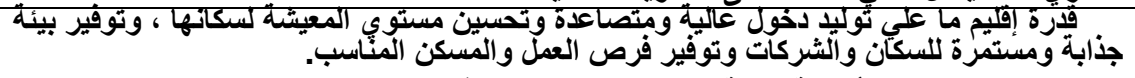 & ${ }^{\left[{ }^{\wedge}\right]}$ Gábor Békés \\
\hline 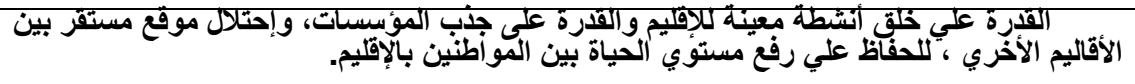 & ستوربر Storper \\
\hline عالي ، وتوفير فرصي توظيف مستمرة لسكان الإقليم:. & Imre LENGYEL \\
\hline 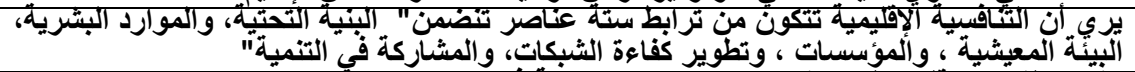 & ${ }^{[r]}$ Sotarauta \\
\hline 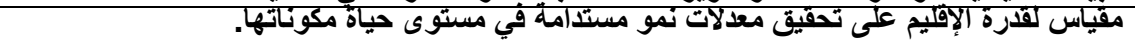 & 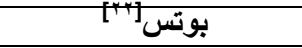 \\
\hline
\end{tabular}

ويري SCOTT وأخرون[با": أن الإقليم التنافسي هو الذي يتخطي ويواجه المنافسة السوقية مع ضمان الإستدامة

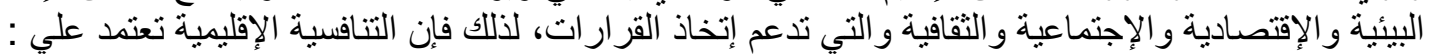

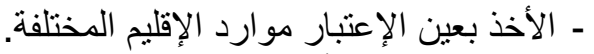

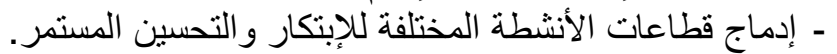

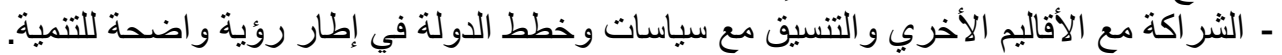
ـ الأخذ بالحسبان الأبعاد الإقتصادية والإنية الإجتماعية والعمر انية لتعزيز عملية التنمية بالإقلية.

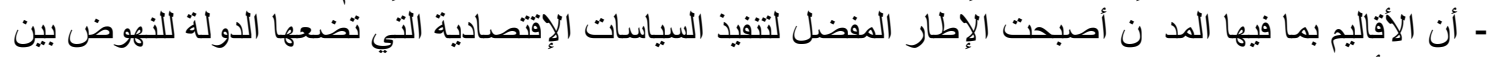
وكما يري CAMAGNI الاخري.

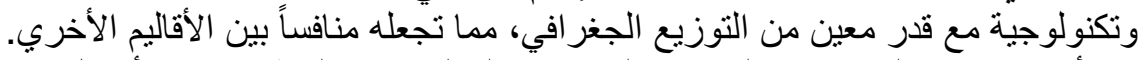

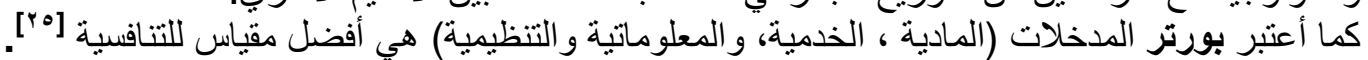

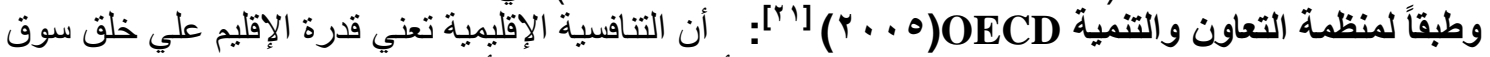

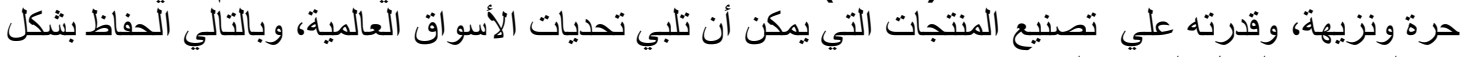
دائم علي زيادة الدخل الحقبقي لسكانه.

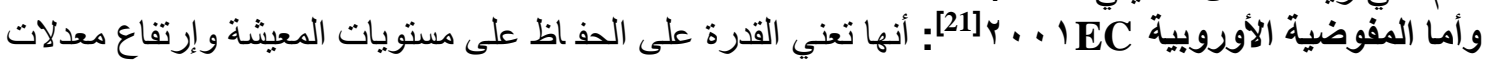
تشغيل العمالة وزيادتها بشكل دائم الماورئه

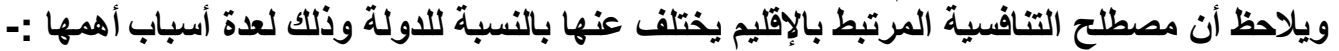
لا يمكن إفتر اض شرط مجموع المبادلات التجارية لتوازن الميزان التجاري لأن المبادلات تتم بين الأقاليم المحلية

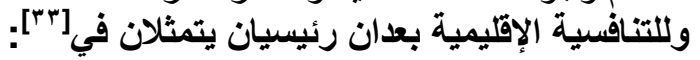

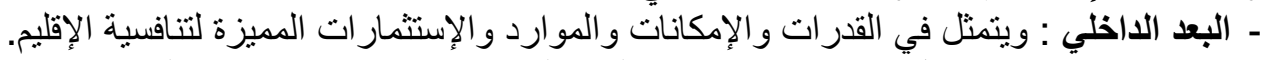

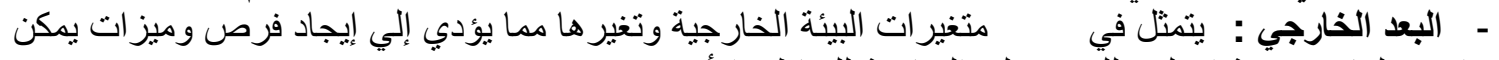

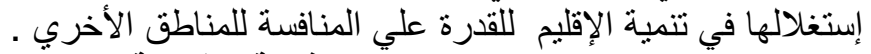

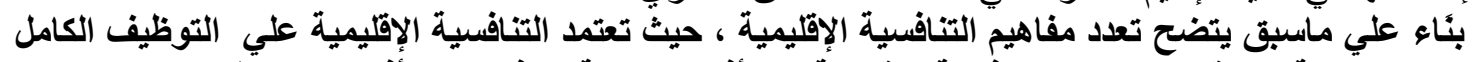
للموارد الكامنة با لإقليم، وتعتبر التتافسية الإقليمية هي أفضل وسيلة لتوفير حياة أفضل للمواطنين ، حيث تكمن 
أهميتها في قدرة الإقليم علي تحقيق ( التقدم الإقتصادي - توفير فرص عمل للجميع - إستدامة التنمية ـ

تحسين مستوي المعيشة للسكان).

ولألك أمكن الوصول إلي مفهوم شامل للتنافسية الإقليمية والتي تعني : قدرة الإقليم علي إستغلال كافة الموارد

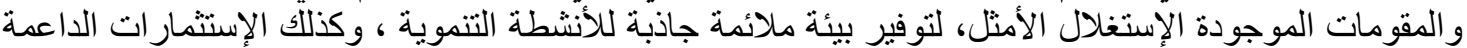

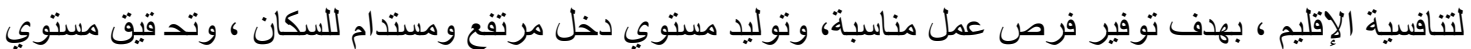

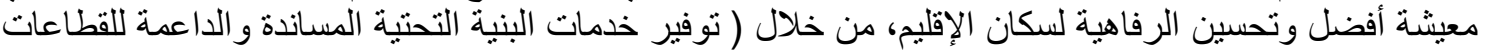

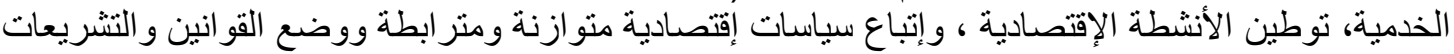

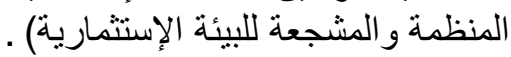

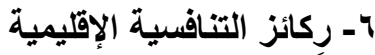
نظر اً لنطورات العولمة المتز ايدة والحاضر الجديد "الإقتصاد القائم علي المعرفة" كانت هناك تحديات الإلت جديدة بدول

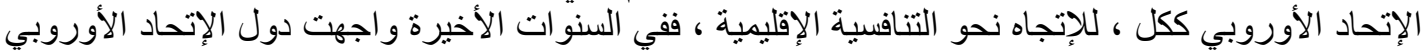

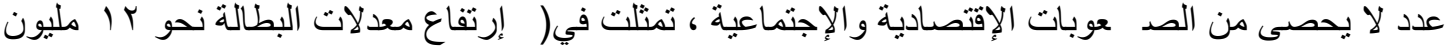

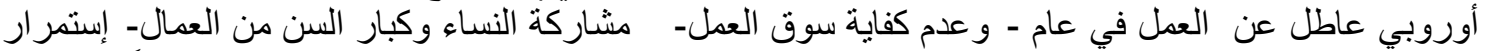

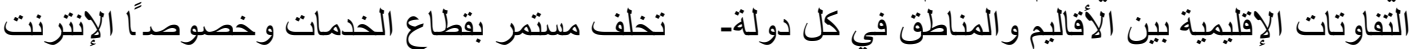

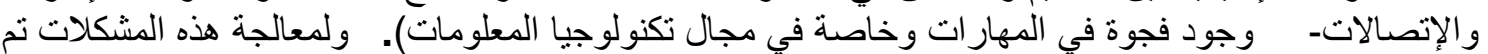

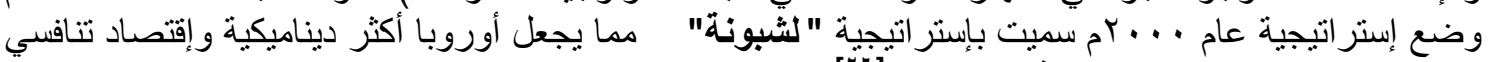

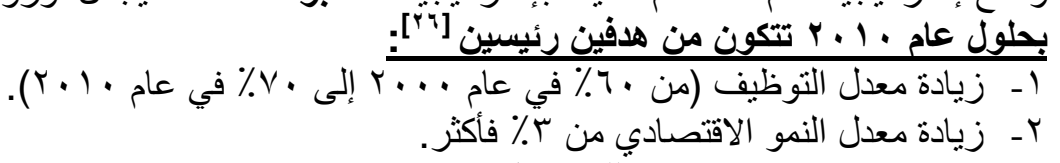

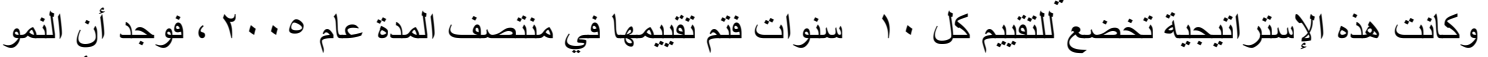

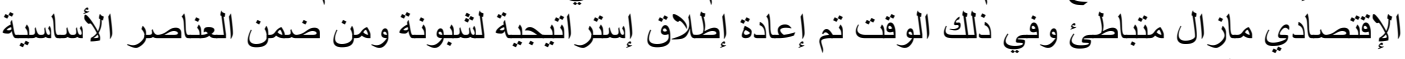

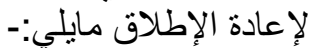

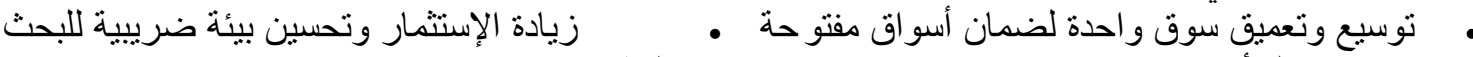

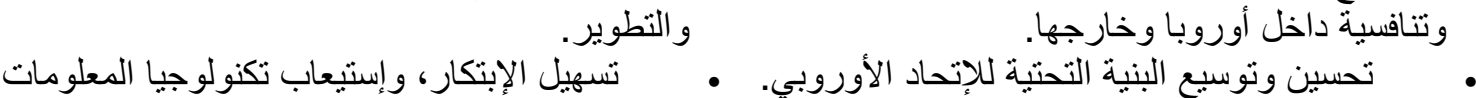
وخفض معدلات البطالة بين الثباب.

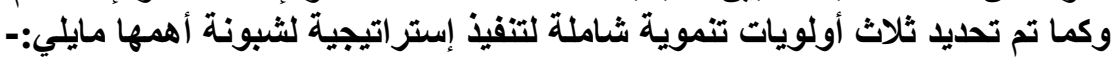

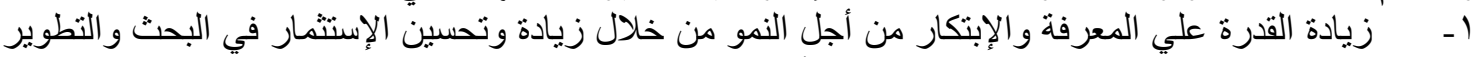
التكنولوجي ، وتسهيل الإبتكار وتعزيز والإنكار ريادة الأعمال.

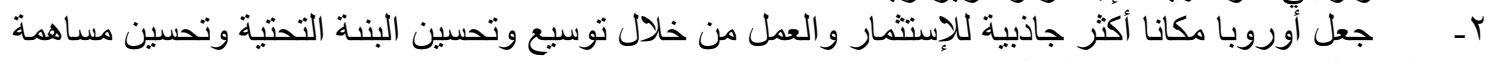

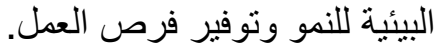

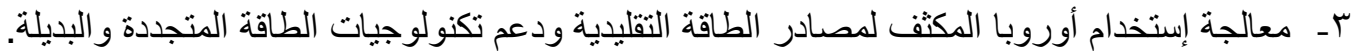

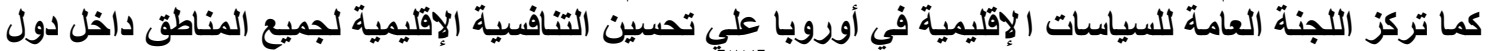

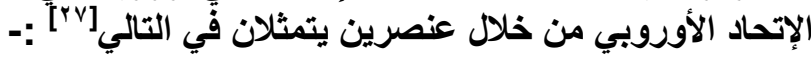

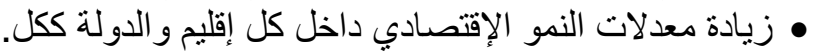

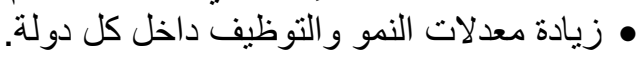

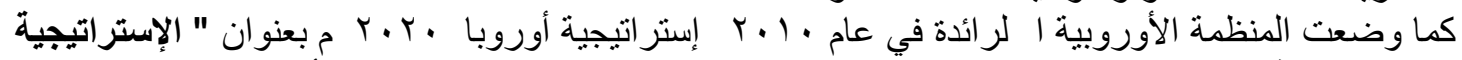

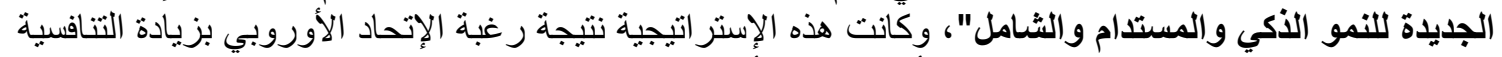

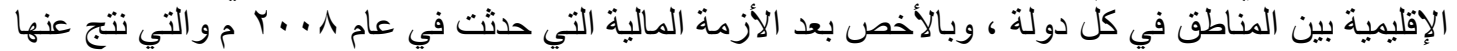

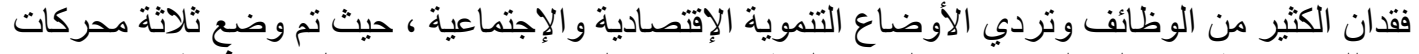

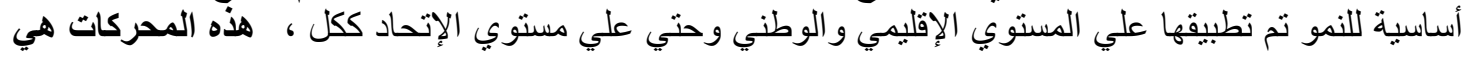

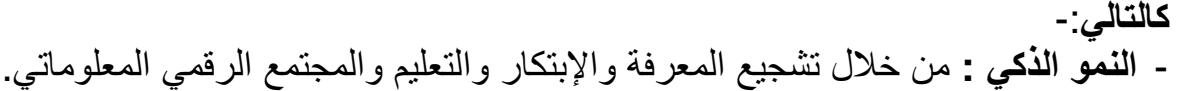

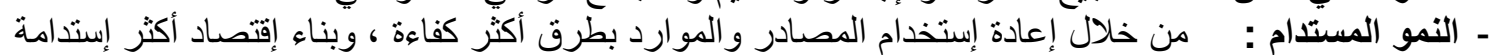

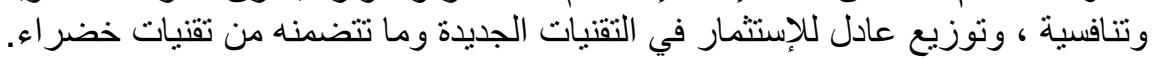


- - النمو الثامل : لبناء مجتم ع منماسك يقوم فيه الثخص بقيادة و إدارة التغيير ومحاربة الفقر و المشاركة في

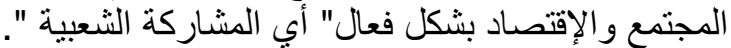
كما تم إطلاق مشاريع تحت مسمي "التوأمة الحفراد الحضرية" من قبل المفوضية الأوروبية بهدف تأسيس أقطاب تنافسية

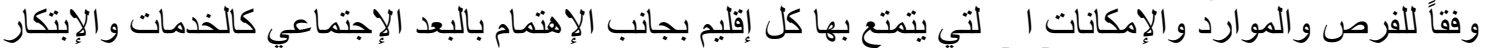

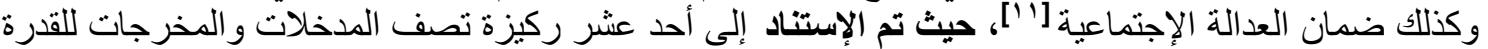

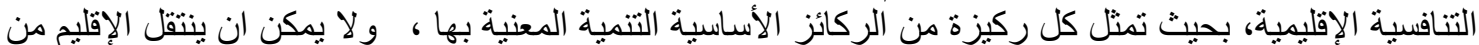

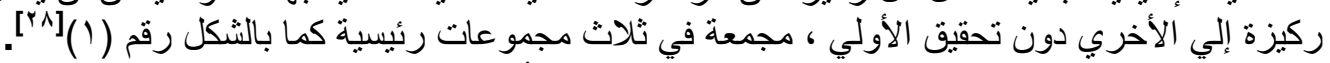

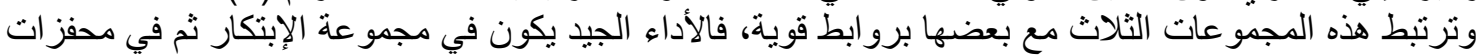

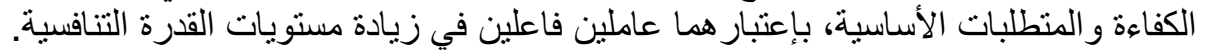

\begin{tabular}{|c|c|c|}
\hline \multicolumn{3}{|c|}{ شكل رقم (1) ركائز التتافسية الإقليمية [^r] } \\
\hline & & \\
\hline بـ تطوير الأعمال والايتكار & 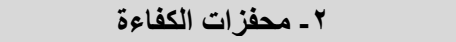 & 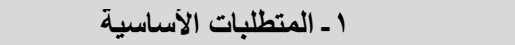 \\
\hline 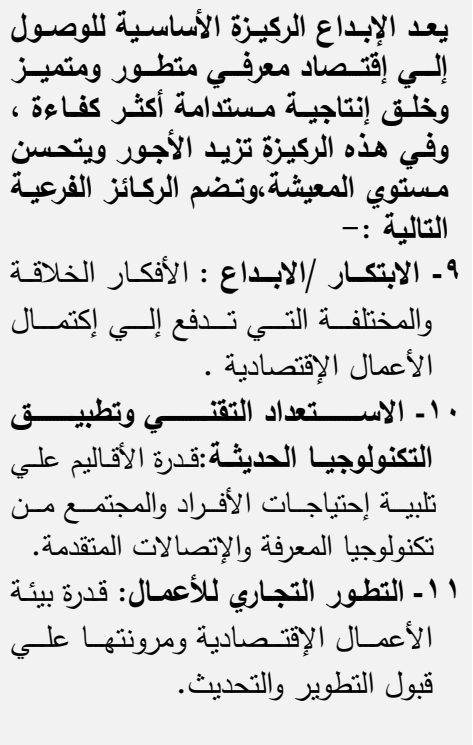 & 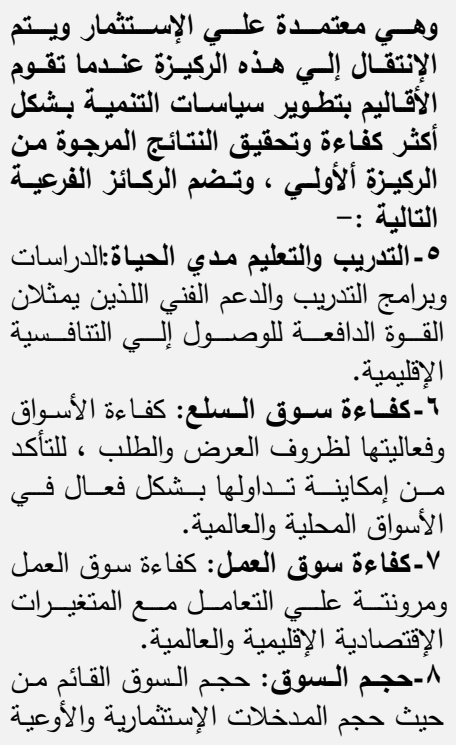 & 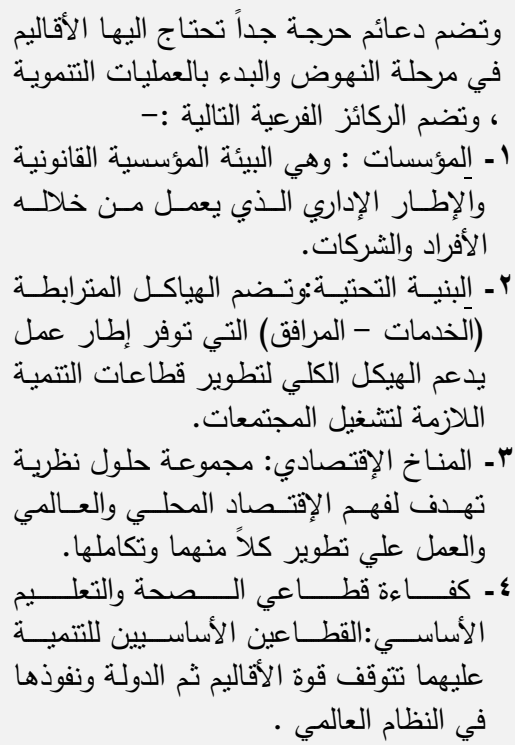 \\
\hline
\end{tabular}

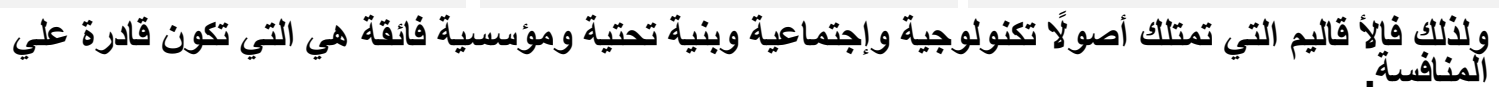

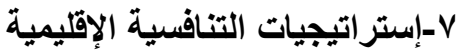

أن الإستراتيجيات التي تهدف إلى تعزيز التنمية الإقليمية ورفع التنافسية الإقليمية هي مهمة تتولاتها هاتية مختلف

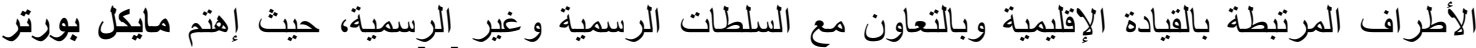

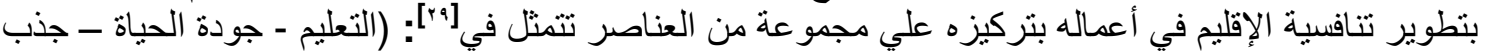

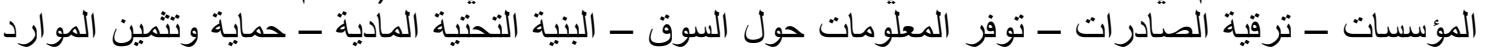

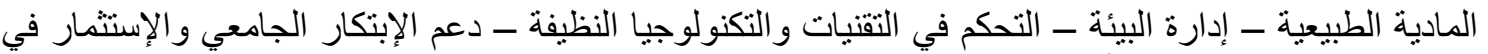

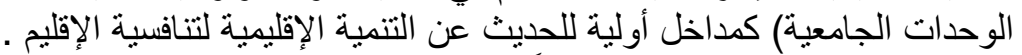

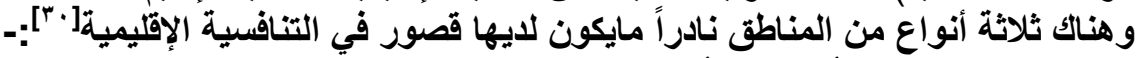

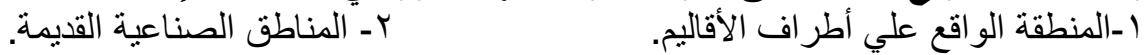

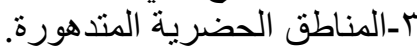

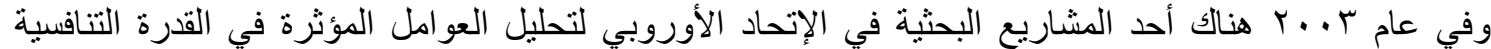

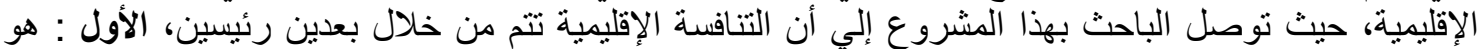
كثافة السكان ، والثاني: معدل نمو الناتج المحلي الإجمالي، وكما تمر التنافسية الإقليمية لأي إقليم بثلاث مراحل 
شكل رقم (r) مر احل التنافسية الإقليمية وفقاً لبورتر

$\downarrow$

بـ-مرطلة خلق المعرفة

وهي مرحلة تتميز بوصول الإقليم إلى الي

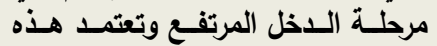

المرحلة علي الإبتكار .

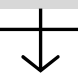

ب-مرحلة نقل المعرفة

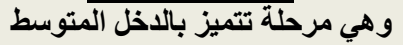

ويحركها الإستثمار .

\section{$\downarrow$}

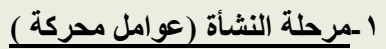

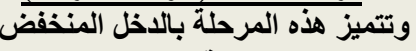

للإقليم.

وكما تركز السياسة الإقتصادية الإقليمية والحكومة الحالية على تعزيز اللبنات الأساسية للنمو داخل كل إقليم

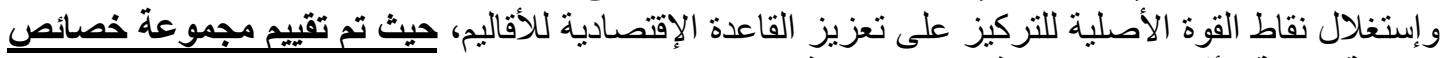

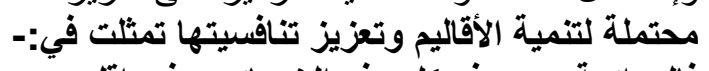
فالموائمة بين هذه كل هذه الخصائص في في إقليم معين يطور إنتاجية العمل ، وئن فيوفر تسويقاً أفضل للأنثطة وما

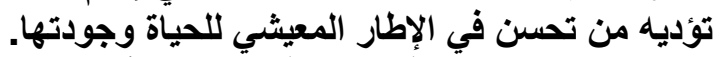

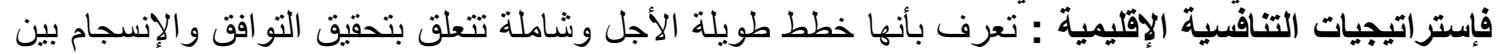

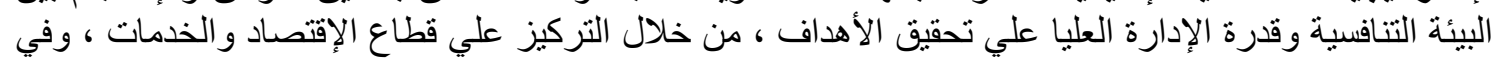

ا. النقل الإسـتراتيجي وتكنولوجيـا الإتصالات والـربط V. البنية التحنية والخدمات النقافية المنطورة .

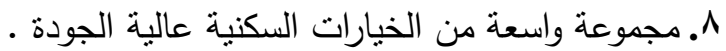

9. البمعة للتميز البيئي.

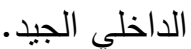

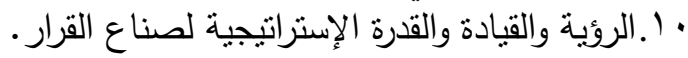

r. القدرة على إتخاذ القرار الإستراتيجي.

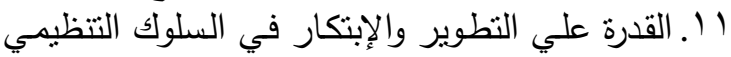

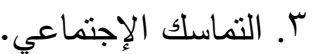

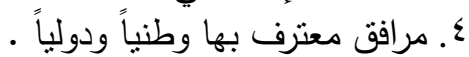

للمدن.

r ا الحوافز المالية المتاحة للإستثمار.

ه. سمعة الأبحاث المتقدمة والتطوير والإبتكار .

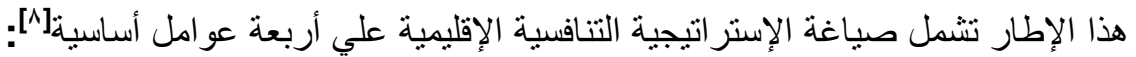
7. سمعة لحوكمة فعالة وكفاءة للخدمات.

$$
\begin{aligned}
& \text { - - نقاط القوة و الضعف. } \\
& \text { - - الفرص و التهديدات. }
\end{aligned}
$$

- - التوقعات الإجتماعية والإقتصادية .

- المشرو عات التنموية للإقليم.

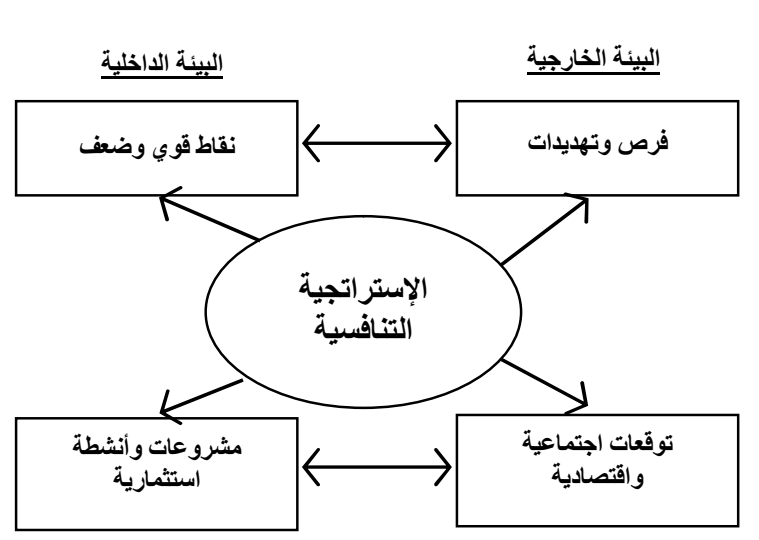

شكل رقم (r) مكونات الإستراتيجية التنافسية

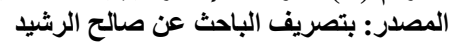

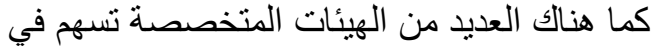

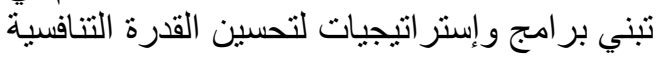
علي المستوي القومي و علي مستوي الوحئ لوحدات

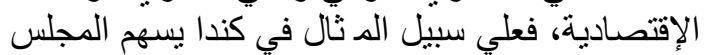

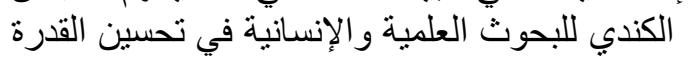

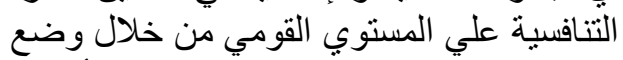

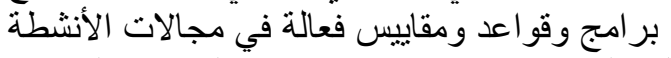
المختلفة الإقتصادية والإجتماعية و العمر انية لتحسين الإنين القدرة التنافسية علي المستوي القومي و الإقلقيمي. حيث يقدم إطار تحليلي لتحسين التنافسية الإقليمية التية

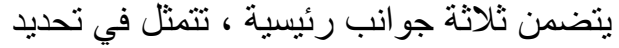

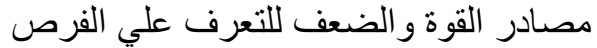
و التحديات ، ورصد المشرو عات المحققة للتنمية لإنية

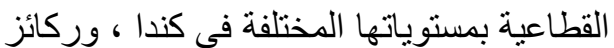

القدرة التنافسية علي المستوي الدولي والإقليمي، وتحديد ال لسياسات اللازمة التي يمكن للحكومة تطبيقها لتحسين القدرة التنافسية للإقليم] [9].

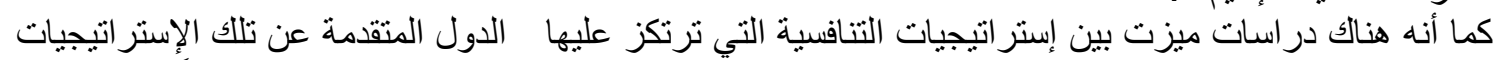

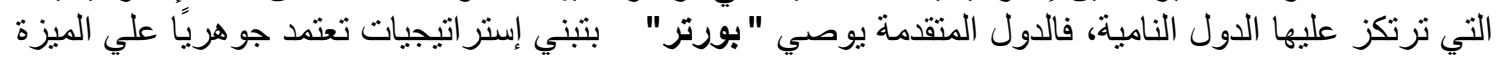




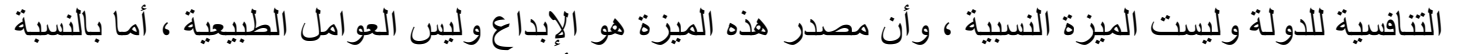

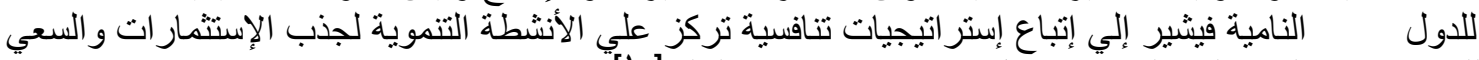

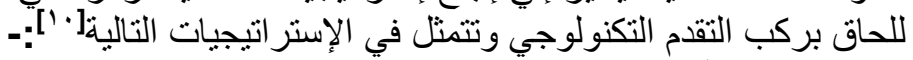

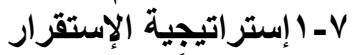
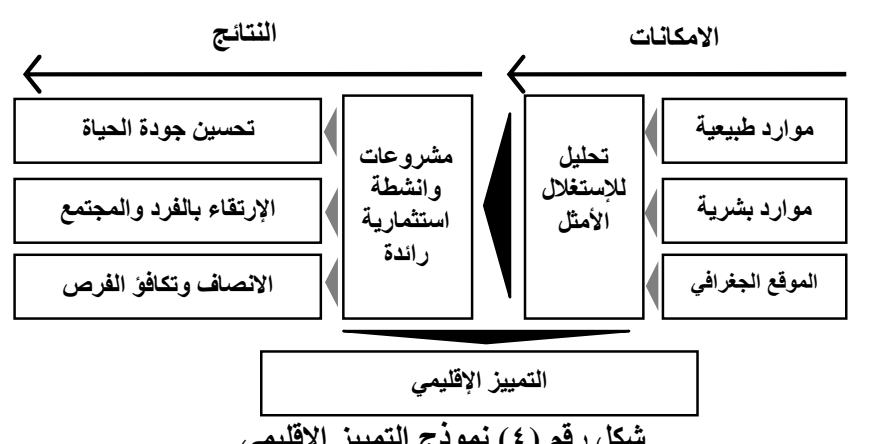

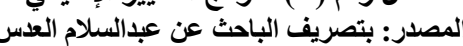

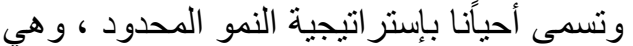

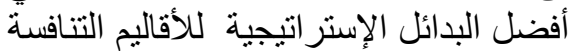
الناجحة ، ووفقًا لهذه الإستر اتيجية تسعى الأقاليج لأليح

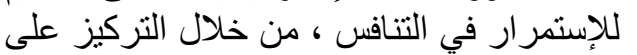

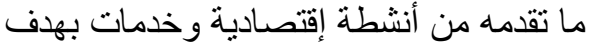
تعزير وتحسين بيئتها التنافسية. Y V-V تعتمد هذه الإستر اتيجية على تقديم خدمات التئز بمستوياتها المختلفة ذات مستوب الإي عالي بالإقلقيم

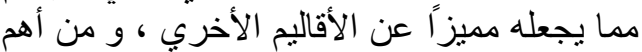

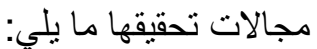
ـ التمييز على أساس التّفوق التكنولوجي. - التمييز على أساس توفير وتقديم خدمات لسكان الإقليم.

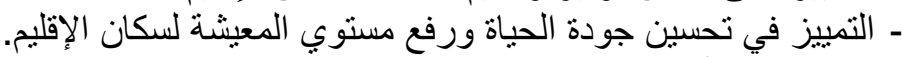

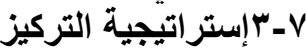

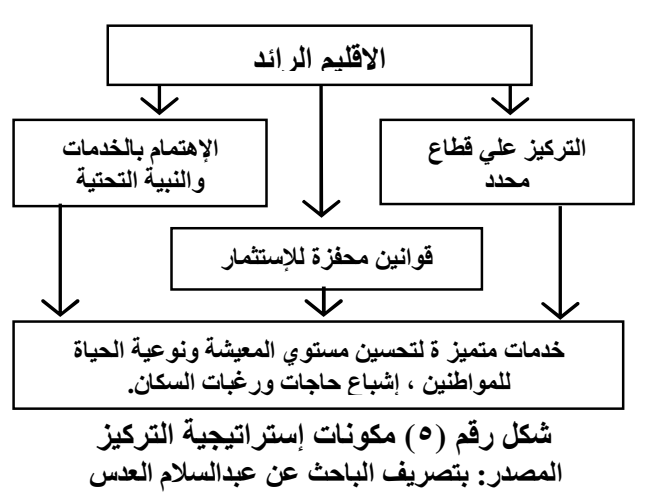

تعني هذه الإستر اتيجية التركيز على قطاع معين من التئن

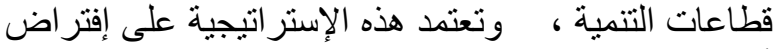

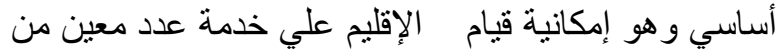

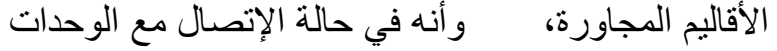
الإقليمية فلابد من التمييز بين المنافسة بين هذه الوحداتئ الوحات،

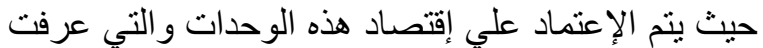

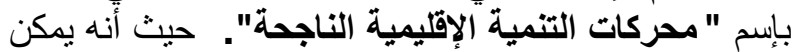

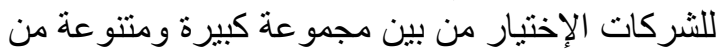

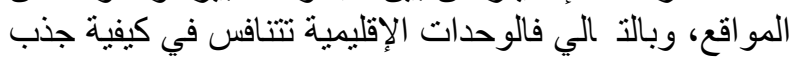

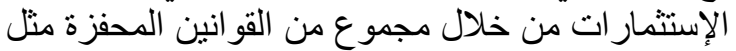

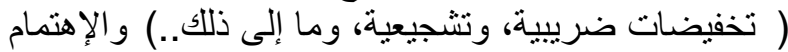

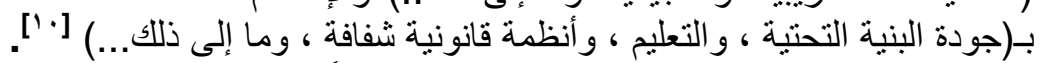

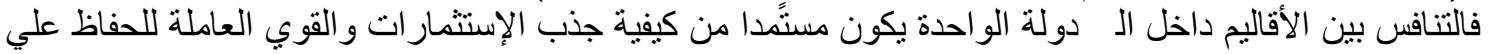

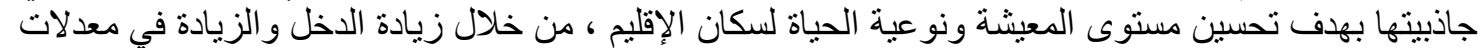

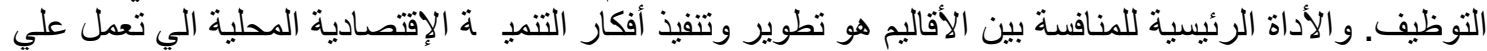

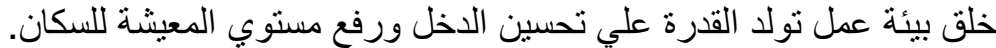

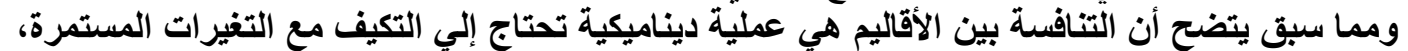

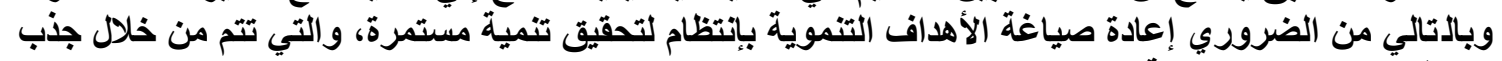
وتوطين المشاريع الناجحة.

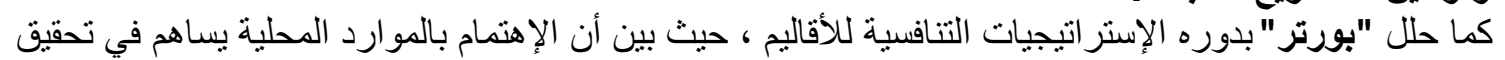

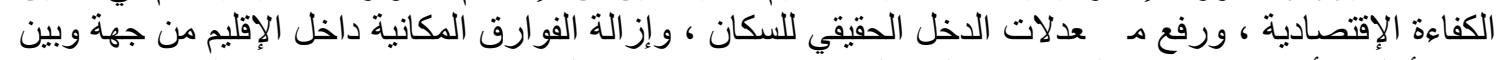

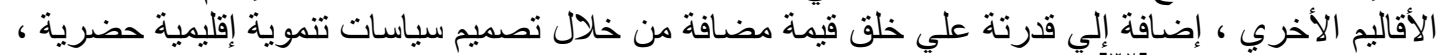

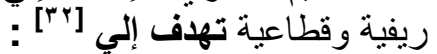

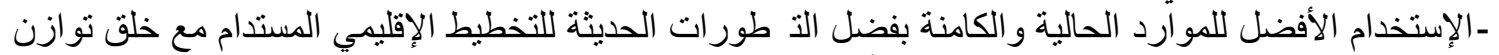

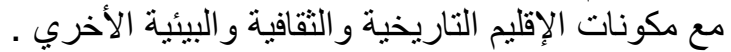
- بناء أقطاب تكنولوجية ، صناعية ، سياحية ، إستشفائية ، تعليمية ، و غير ها علي أساس التنوع و التكامل التنموي لخلق ميزة تنافسية للإقليم مع التركيز علي الأنشطة التنموية. 
التركيز علي تعزيز البنية التحنية المادية كوسائل النقل والبنية التكنولوجية الإفتراضية التي تسمح بإنسيابية

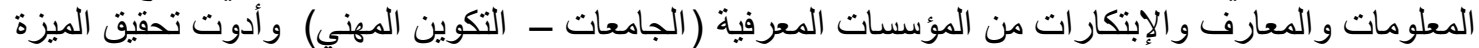

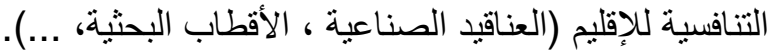

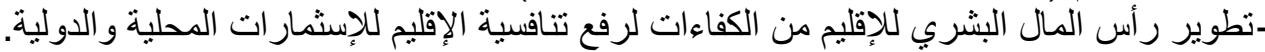

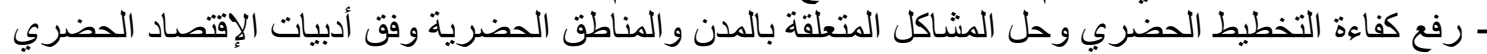
الذي يعد أحد فروع الإقتصاد الإقليمي.

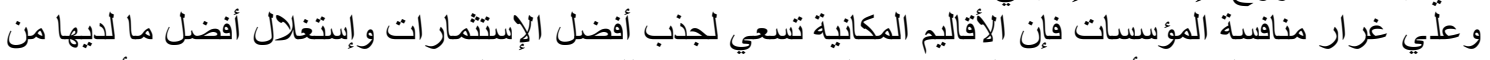

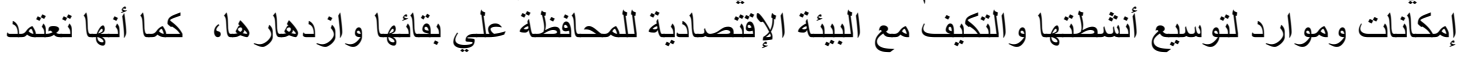

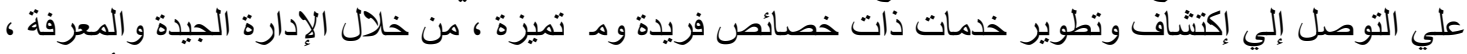

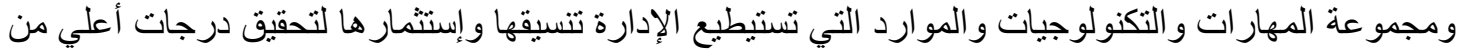

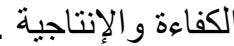

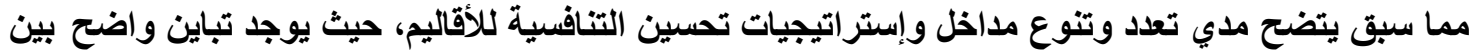

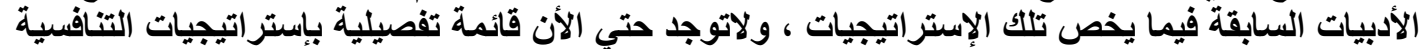

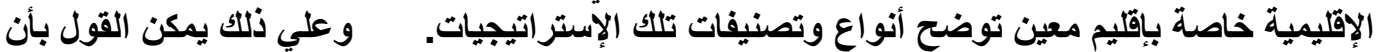

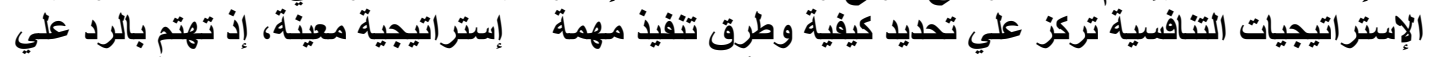

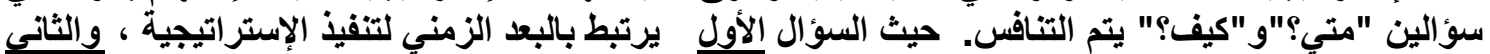

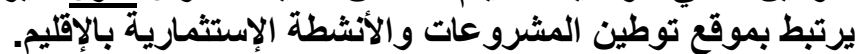

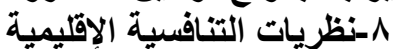
تمثلت نظريات التنافسية الإقليمية في التالي:-

1- انظرية إقتصاديات التنمية

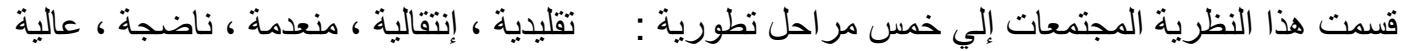

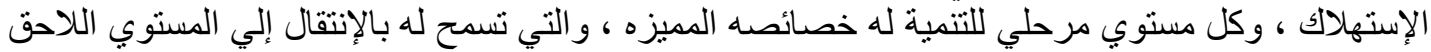

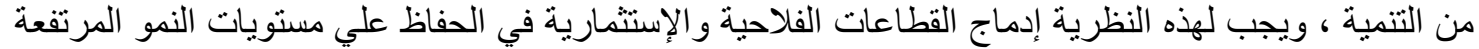

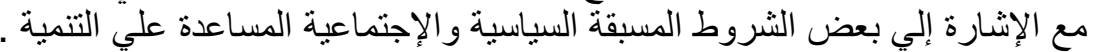

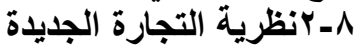

تفرض نظرية التجارةً وفقا لإعتبار ات أهمها أن عملية التجارة تحدث فقط بين بلدين ذات عو امل تكنولوجية مختلفة ووصلت

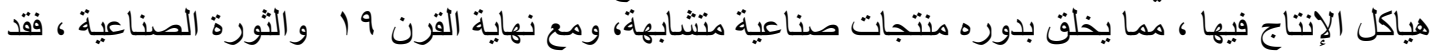

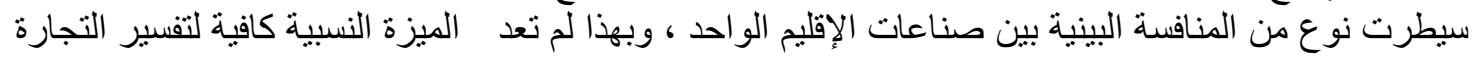

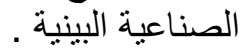

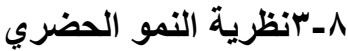
قدم JANE JACOBS نظرية النمو الحضري عام 1979 مام، و هي عبارة عن نظرة إقتصادية و إجتماعية مؤثرة

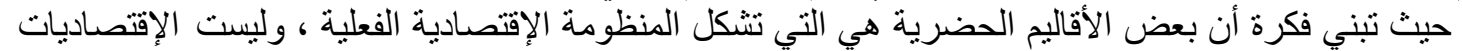

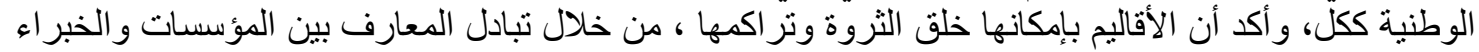

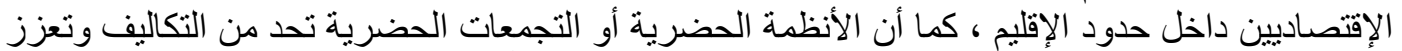

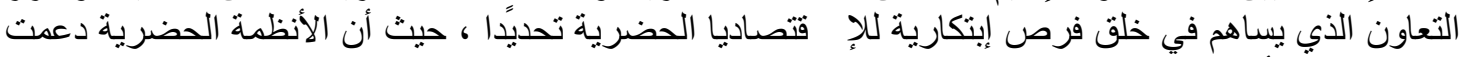

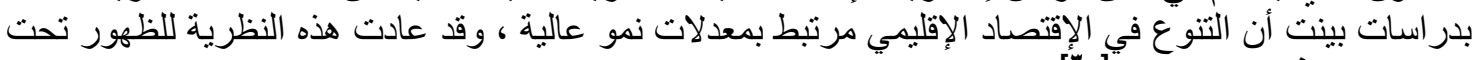

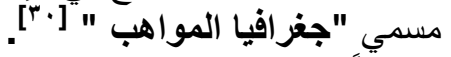

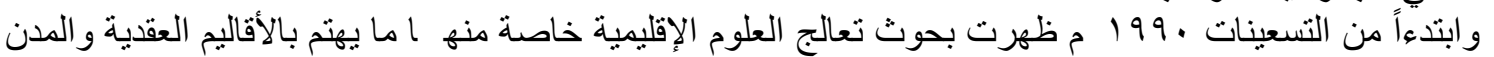

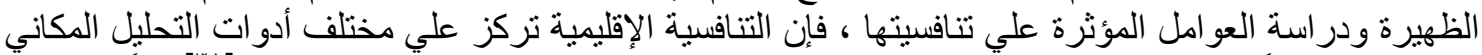

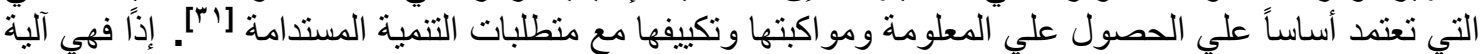

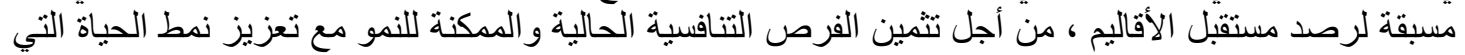
تر اعي تحديات التنمية المستدامة.

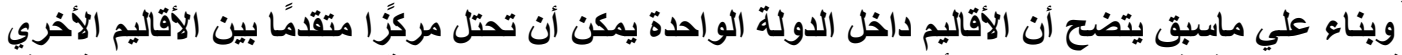

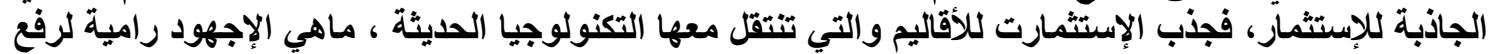




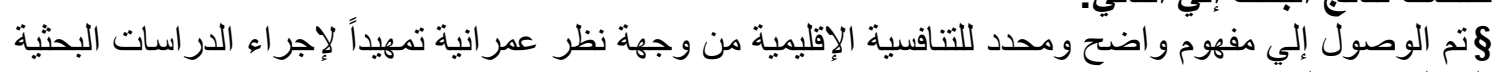
المتعلقة بهذا الموضو المي مفوع فيما بعد.

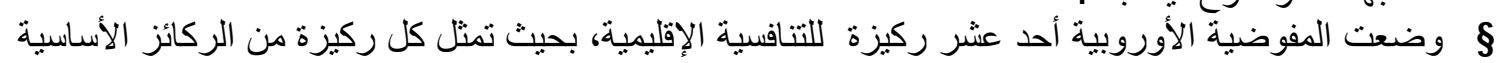

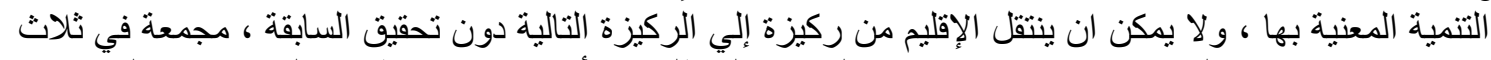

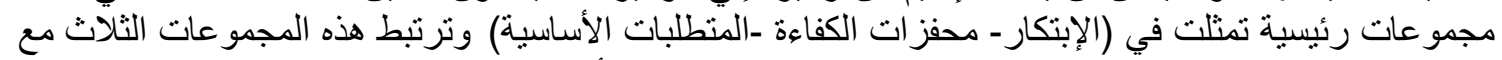

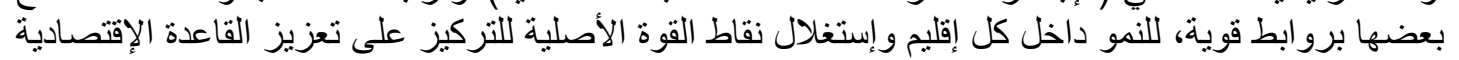

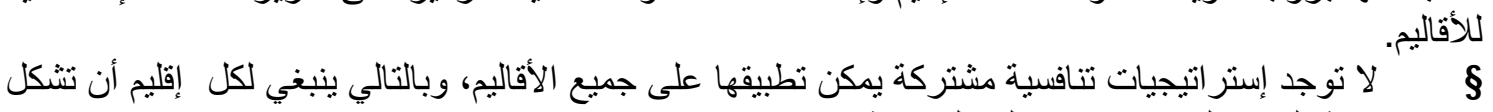
الإستر اتيجية الفريدة لزيادة قدرة الإقليم التنتافسية.

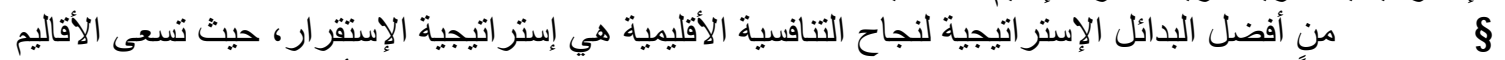

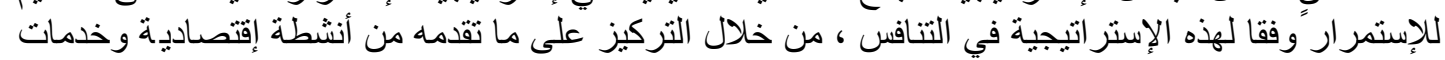

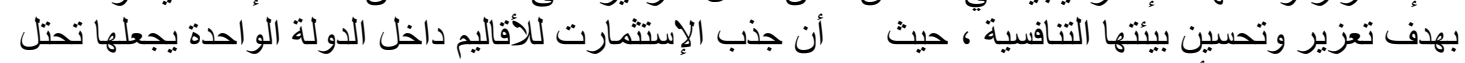

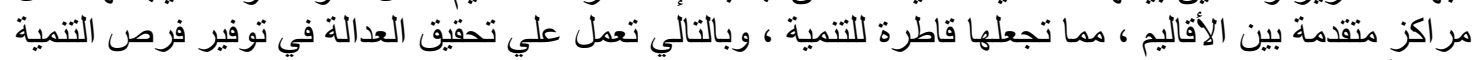

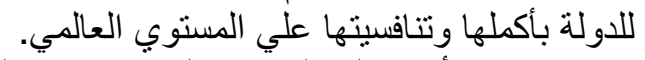

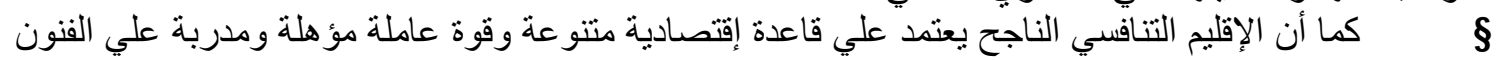

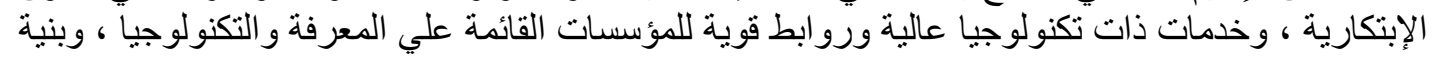
تحيتة منظورة وحديثة وجودة عالئة للبيئة العمر انية المبنية .

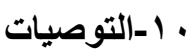

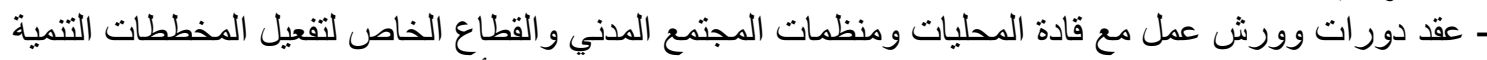

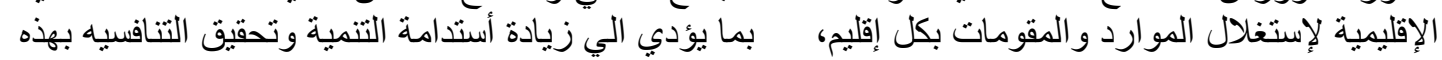

- - تكوين شبكة من الهيئات المتخصصة للتنافسية الإقليمية تسهم في تبني بر امج و إستر اتيجيات وسياسات لتحسين

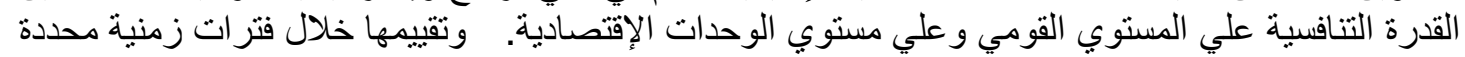

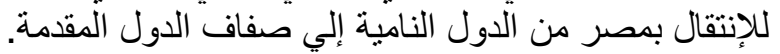

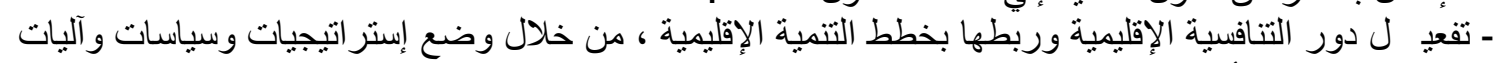
لتحسين تنافسية الأقاليم و الإرتقاء بتنمينها.

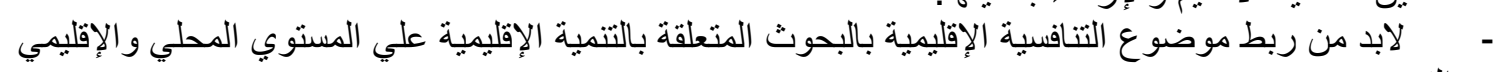
و القومي.

\section{1 - الامهوامش}

1-بوري منير-تحليل التنافسية العربية في ظل العولمة الإقتصادية- مجلة شمال افريقيا عدد ع ـالجزائر -صدوه.

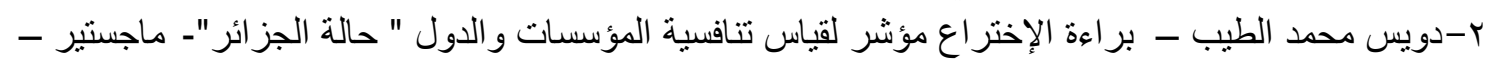

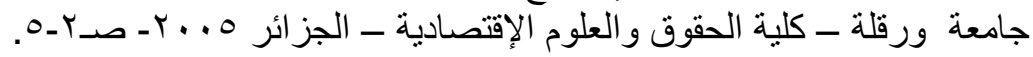

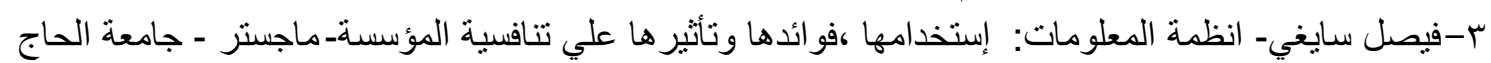

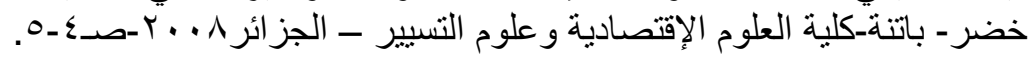

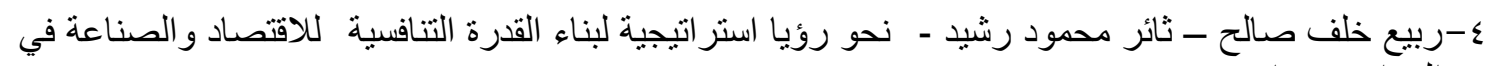
العراق -بغداد.

ه-علي توفيق الصادق ـ المنافسة في ظل العولمة - ـ القدرة التنافسية للإقتصاديات العربية في الأسواق العالمية

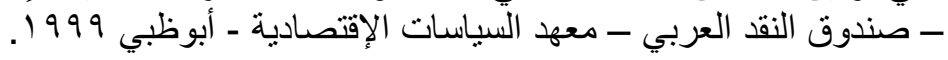

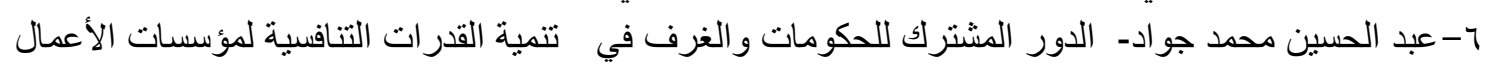

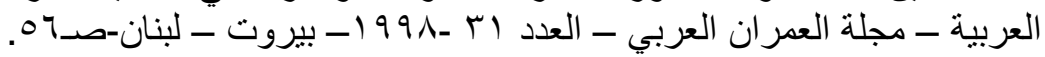




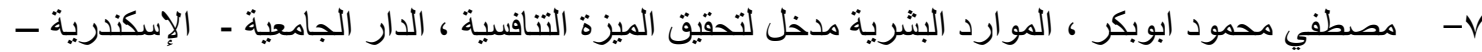

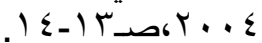

$$
\begin{aligned}
& \text { ي-فلاح الحسيني- الإدار اة الإستراتيجية : مفاهيمها ـ مداخلها ـ عمليات المعاصرة ـ الطبعة الأولي ، دار الوائل }
\end{aligned}
$$

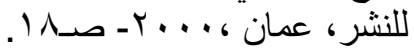

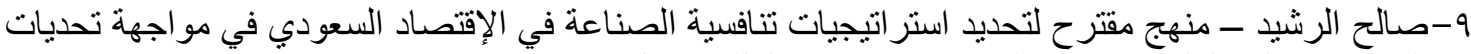

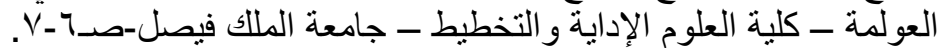

$$
\begin{aligned}
& \text { • - عبد السلام العدس ، آزاد قاسم - الإستر اتيجيات الكلية في نطاق السوق المحلي والأسواق العالمية - } \\
& \text { سوريا. } \\
& \text { 11- المركز المصري للإراسات الإقتصادية - الإقتصاد المصري في ضوء نتائج نقرير التتافسية العالمي }
\end{aligned}
$$

12-Jurgita Bruneckiene,Andrius Guzavicius, Renata Cincikaite -Measurement of Urban Competitiveness in Lithuania-Inzinerine Economic-Engineering Economics,2010P226-331.

13-Estienne, Liefoogue, Paris (2009); « Economic ET attractive: une nouvelle production urbane in Paris»; Lille Metropolis Laboratories du renouveau urbain, Parenthèses, p. 51-53.

14-Begg (1999). "Cities and Competitiveness", Urban Studies, p.44.

15-Rogerson, "Quality of Life and City Competitiveness". Urban Studies, (1999), p (969-985).

16-Janne Antikainen, Nordregio .The role, specific situation and potentials of urban areas as nodes in a polycentric development-ESPON Project-Second interim report-SWEDEN $r \ldots r, \mathrm{P}^{\vee} \varepsilon$.

17- Bruneckienè, J.; Guzavičius, A.; Činčikaitè, R. r.1. Measurement of Urban Competitiveness in Lithua-nia. Inzinerine Ekonomika $r^{\prime}(0): p 0 \cdot p_{-} \leqslant q r$

18-Gábor Békés. Measuring regional competitiveness: A survey of approaches, measurement and data-Institute of Economics - Centre for Economic and Regional Studies Hungarian Academy of Sciences- r. 10P220-223.

19-Storper, M. 199v. The Regional World; Territorial Development in a Global Economy. New York/ Lon-don: The Guilford Press, p. rr^.

20-Imre LENGYEL-Y... . . An Attempt for the Measurement of Regional Competitiveness in Hungary-conference on "Enlargement, Southern Europe and the Mediterranean" 46 The Congress of the European Regional Science Association, pp. 13-38.

21-Vladimir Burkov, Nar mantas Kazimieras. $r \cdot 1$ r.COMPETITIVE URBAN DEVELOPMENT MODEL.Vilnius Gediminas Technical University.P43.

22-SILVIA Rucinska -RASTISLAV RUČINSKÝ- Factors of regional competitiveness -Central European Conference in Regional Science - CERS,- Technical University of Kosice, Faculty of Economics-2007.P22-25.

23-Scott, Storper. (2007), « Regions, globalization, development », in: Regional Studies: pp 579.

24-CAMAGNI ;R. (2003), " Competitive territorial, milieu locaux et apprentissage collectif : une contre-réflexion critique »; in : Revue d'Economie Régionale et Urbaine, p.556.

25-PORTER, M. (2001) "Regions and the new economics of competition », in: A. Scott; Global City-regions: Trends, Theory, Policies New York: Oxford University Press p 139-157.

26-Centre for Rural Economy-Rural Areas and Regional Competitiveness- Research Report-Report to Local Government Rural Network-University of New Castel upon Tyne 2005.

27-Michael Parkinson - James Simmie, Competitive European Cities: Where do the Core Cities Stand @Office of the Deputy Prime Minister: London2004- P. 17.

28-PaolaAnnoni 'Lewis Dijkstra and Nadia Gargano-The EU Regional Competitiveness Index 2016 Working Papers - A series of short papers on regional research and indicators produced by the Directorate-General for Regional and Urban Policy-2017.P112-120. 
29-PORTER M; « Location, Competition, and Economic Development: Local Clusters in a Global Economy», The global competitiveness report, World economic forum, Oxford University- $r \ldots$ - pp 17-20.

30-SCOTT. (2006), « Les regions et l'économie Mondale », 3ème edition؛ L'Harmattan, p.188.

31-Lithia's . Varlet. \& !Vicente.(2005); « TIC ET reorganization spatial des activities economies: introduction », in: Geographies, economies ET society. p.52.

32-http://www.cairn.info/revue-l-economie-politique-2007-1-page-41.htm consult le.

\section{3-http://blogs.ksu.edu.sa/sunhat/2000}

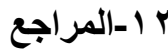

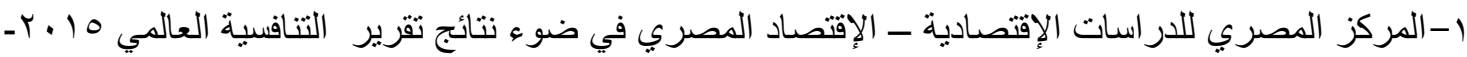

$$
\begin{aligned}
& r+17 \\
& \text { r-ربيع خلف صالح - ثائر محمود رشيد - نحو رؤيا استر اتيجية لبناء القدرة التنافسية للاقتصاد و الصناعة في } \\
& \text { العراق -بـغ خداد. } \\
& \text { ب-صالح الرشيد - منهج مفترح لتحديد استر اتيجيات تنافسية الصناعة في الإقتصاد السعودي في مواجهة تحديات }
\end{aligned}
$$

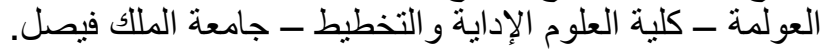

$$
\begin{aligned}
& \text { ع - عبد الحسين محمد جو اد- الدور المشترك للحكومات والغرف في تلتمية القدر ات التنافسية لمؤسسات الأعمال }
\end{aligned}
$$

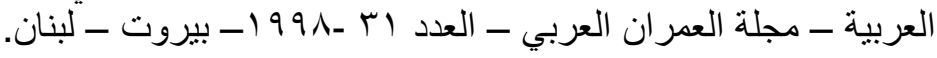

$$
\begin{aligned}
& \text { ه-علي توفيق الصـادق - المنافسة في ظل العولمة - ـ القدرة التنافسية للإقتصاديات العربية في الأسواق العالمية }
\end{aligned}
$$

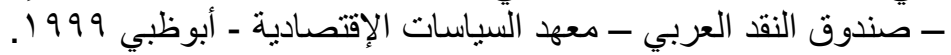

$$
\begin{aligned}
& \text { ج-عبد السلام العدس ، آزاد قاسم - الإستر اتيجيات الكلية في نطاق السوق المحلي والأسواق العالمية - سوريا. } \\
& \text { V-فريد أحمد عبدالعال- اليات تحقيق سياسة التنمية الإقليمية المتوازنة في مصر - - معهد التخطيط القومي - }
\end{aligned}
$$

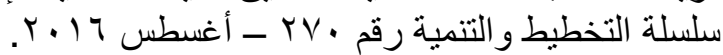

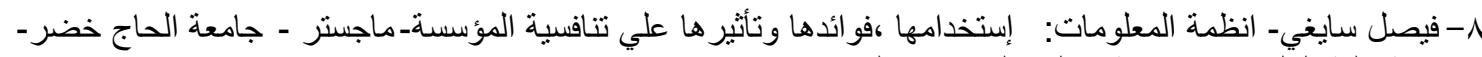

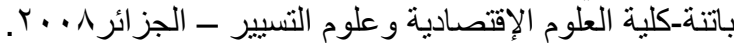

$$
\begin{aligned}
& \text { 9- فلاح الحسيني- الإدار اة الإستر اتيجية : مفاهيمها ـ مداخلها ـ ـ عمليات المعاصرة ـ ـ الطبعة الأولي ، دار الو ائل للنشر، }
\end{aligned}
$$

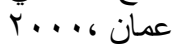

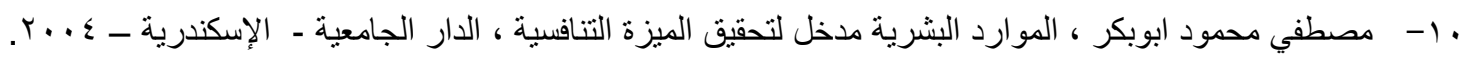

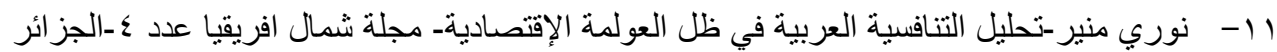

12-Begg (1999). "Cities and Competitiveness", Urban Studies.

13-Bruneckienè, J.; Guzavičius, A.; Činčikaitè, R. Y.1. Measurement of Urban Competitiveness in Lithua-nia. Inzinerine Ekonomika Y)(0).

14-Centre for Rural Economy-Rural Areas and Regional Competitiveness- Research Report-Report to Local Government Rural Network-University of New Castel upon Tyne 2005.

15-CAMAGNI ;R. (2003), « Competitive territorial, milieu locaux et apprentissage collectif : une contre-réflexion critique »; in : Revue d'Economie Régionale et Urbaine.

16-Estienne, Liefoogue, Paris (2009); " Economic ET attractive: une nouvelle production urbane in Paris»; Lille Metropolis Laboratories du renouveau urbain, Parenthèses.

17-Gábor Békés. Measuring regional competitiveness: A survey of approaches, measurement and data-Institute of Economics - Centre for Economic and Regional Studies Hungarian Academy of Sciences- $r \cdot 10$.

18-Imre LENGYEL - $r \ldots$.. . An Attempt for the Measurement of Regional Competitiveness in Hungary-conference on "Enlargement, Southern Europe and the Mediterranean" 46 The Congress of the European Regional Science Association.

19- Janne Antikainen, Nordregio .The role, specific situation and potentials of urban areas as nodes in a polycentric development-ESPON Project-Second interim report-SWEDEN $r \cdots r$.

20-Jurgita Bruneckiene,Andrius Guzavicius,Renata Cincikaite-Measurement of Urban Competitiveness in Lithuania-Inzinerine Economic-Engineering Economics, 2010.

21-Lithia's . Varlet. \& !Vicente.(2005); « TIC ET reorganization spatial des activities economies: introduction », in: Geographies, economies ET society. 
22- Michael Parkinson - James Simmie, Competitive European Cities: Where do the Core Cities Stand @Office of the Deputy Prime Minister: London2004.

23- PORTER M; « Location, Competition, and Economic Development: Local Clusters in a Global Economy», The global competitiveness report, World economic forum, Oxford University- $r$...

24-PORTER, M. (2001) "Regions and the new economics of competition », in: A. Scott; Global City-regions: Trends, Theory, Policies New York: Oxford University Press .

25- PaolaAnnoni 'Lewis Dijkstra and Nadia Gargano-The EU Regional Competitiveness Index 2016 Working Papers - A series of short papers on regional research and indicators produced by the Directorate-General for Regional and Urban Policy-2017.

26- Rogerson, "Quality of Life and City Competitiveness". Urban Studies, (1999).

27-Storper, M. 199v. The Regional World; Territorial Development in a Global Economy. New York/ Lon-don: The Guilford Press.

28- Scott, Storper. (2007), « Regions, globalization, development », in: Regional Studies.

29-SCOTT. (2006), « Les regions et l'économie Mondale », 3ème edition؛ L'Harmattan.

30-SILVIA Rucinska-RASTISLAV RUČINSKÝ- Factors of regional competitiveness

-Central European Conference in Regional Science - CERS,- Technical University of Kosice, Faculty of Economics-2007.

31-Vladimir Burkov, Nar mantas Kazimieras. $r \cdot 1$ r.COMPETITIVE URBAN

DEVELOPMENT MODEL.Vilnius Gediminas Technical University.

32- http://www.cairn.info/revue-1-economie-politique-2007-1-page-41.htm consult le.

33- http://blogs.ksu.edu.sa/sunhat/2000 